\title{
OS DESAFIOS PARA AS CIÊNCIAS SOCIAIS EM TEMPOS DE (DES) INVESTIMENTOS
}

\author{
Cacildo Teixeira de Carvalho Neto* \\ Helen Barbosa Raiz Engler**
}

RESUMO: O objetivo deste texto é trazer à baila o debate das ciências sociais na atualidade e o rebatimento em sua realização diante os (des) investimentos financeiros do Estado e a visão mercadológica nessa relação. Para a construção do texto utilizou-se do método dialético; com percurso metodológico na abordagem qualitativa e pesquisa bibliográfica. Como resultado revelam-se baixos investimentos para as ciências sociais, pois trata-se de conhecimento humano e científico que não desperta interesse ao capitalismo, por não produzir mercadoria e não gerar consumo. Mas com relevância na construção de conhecimento científico capaz de desvelar as relações sociais e criar novas possibilidades de desenvolvimento humano.

PALAVRAS-CHAVE: Estado; capitalismo; Ciências sociais.

\section{CHALLENGES FOR THE SOCIAL SCIENCES IN (DE)-INVESTMENT TIMES}

\begin{abstract}
The current role of Social Sciences is debated, coupled to its performance in the State's (de)-investment times and the marketology aspect of such relationships. The dialectic method was employed with a qualitative approach and bibliographic research. Results reveal low investment rates for Social Sciences due to the fact that human and scientific acknowledgement does not interest capitalism. In fact, goods are not manufactured and consumption is not created. However, the construction of scientific knowledge capable of revealing social relationships and establishing new types of human development is greatly relevant.
\end{abstract}

KEY WORDs: State; Capitalism; Social Sciences.

\footnotetext{
* Assistente Social do Hospital de Clínicas da Universidade Federal do Triângulo Mineiro. Doutor em Serviço Social pela Faculdade de Ciências Humanas e Sociais, Unesp Campus Franca/SP, Brasil. E-mail: cacildoneto37@gmail.com

*** Livre-docente. Docente da Graduação em Serviço Social e do Programa de Pós-Graduação em Serviço Social da Faculdade de Ciências Humanas e Sociais, Universidade Estadual Paulista (Unesp), Campus Franca/SP, Brasil.
} 


\section{INTRODUÇÃO}

O objetivo proposto para este texto é apresentar uma análise dos desafios presentes na construção das ciências no Brasil diante o desmonte das políticas públicas de educação e dos parcos investimentos destinados às pesquisas nas ciências sociais, consequentemente nas universidades e programas de pós-graduação, o que revela um desinvestimento, sem parênteses, do governo nos últimos anos.

Considera-se que na história da humanidade a ciência se apresenta como fruto do desenvolvimento humano em suas potencialidades; o resultado da busca incessante de respostas pelo desconhecido, a desconstrução e reconstrução daquilo já revelado; bem como de sua interação com o meio natural e social para suprir suas necessidades. O ser humano é um constante vir a ser nas transformações das relações sociais e na vida planetária. Ser em transformação contínua é a representação objetiva e subjetiva daquilo que foi, é, e ainda será, pois é nas relações construídas a partir da capacidade humana que está a ciência. De acordo com Andery et al. (2014, p. 13), "A ciência caracteriza-se por ser a tentativa do homem de entender e explicar racionalmente a natureza, buscando formular leis que, em última instância, permitem a atuação humana."

A ciência é compreendida como fruto da ação intelectual e material do homem, entendida como a expressão da criação humana e é a partir dessa compreensão da capacidade do ser humano de criar e renovar o conhecimento que alicerça a ciência. Com isso, o desafio presente nesse trabalho é elucidar a ciência enquanto caminho de novas criações para a humanidade, a possiblidade de se reinventar na história mesmo que os baixos investimentos públicos e a lógica de mercado reverberem em sua materialização. Aqui, serão tomadas as ciências sociais como objeto de estudo e reflexão.

\section{ALGUMAS ANOTAÇÕES TEÓRICAS E CONCEITUAIS}

Pensar a ciência social é considerá-la enquanto expressão da capacidade humana em desvelar o desconhecido, reelaborar o versado, um constante vir-a- 
ser da realidade. A ciência social tem esse papel, o de revelar os fenômenos, as aproximações sucessivas da realidade social - as iterações sociais a partir das relações entre os seres humanos -, no seu tempo e espaço.

O objeto das ciências sociais é por si só histórico, sendo que tal característica exprime sua imprevisibilidade, uma constante fermentação do fenômeno que está neste tempo, neste espaço, ou seja, "A provisoriedade processual é a marca básica da história, significando que as coisas nunca ‘são' definitivamente, mas ‘estão' em passagem, em transição” (DEMO, 2010, p. 15).

A história nos mostra que a realidade dos povos em determinado espaço e tempo têm características comuns, traços culturais, políticos e sociais que mostram semelhanças, mas também dissonâncias na construção das relações sociais. Aqui compreendem-se as relações sociais como todas as formas de relações construídas entre seres humanos, seja de cunho produtivo e reprodutivo, objetivo e subjetivo, espiritual e material.

Assim, as relações sociais são toda e qualquer forma de relação, interação, comunicação, expressão que os seres humanos estabelecem entre si, nas mais diversas formas e possibilidades de viver em comunidade; nos diferentes espaços, nas variadas formas de expressar seus valores e crenças; na arte de viver em tempo de barbárie e na reconstrução da vida. Essa relação é condicionada pela consciência histórica desses sujeitos, pois,

Fazemos história, sem dúvida, mas em condições dadas, que geralmente são mais fortes que nossas ideias. Mas isto não retira o traço profundo de que podemos ter consciência histórica de nossos condicionamentos. O fato de que a história não somente acontece, mas em parte pode ser 'feita' acontecer, pode ser relativamente planejada, pode-se intervir nela com maior ou menor êxito, mostra que se trata de realidades muito diversas. As realidades materiais não têm consciência de si mesmas. Por mais que possamos mostrar que a 'vontade própria' é menos do que imaginamos, desde que exista, já constitui uma diferença capital. (DEMO, 2010, p. 16).

Como bem explicitado por Pedro Demo, a realidade é consubstanciada por condicionamentos históricos intrínsecos a ela, que permeiam todas as relações sociais. Ao nascer, o ser humano faz parte de uma determinada sociedade com 
traços culturais, econômicos, políticos e sociais já construídos. Entretanto, tais condicionamentos não são estanques, imutáveis, são fenômenos produzidos pelas e nas relações sociais e podem ser reconstruídos a partir e por um coletivo social pertencente nessa mesma sociedade. Tal compreensão explica o caráter contraditório da sociedade, o ser humano é capaz de desconstruir e reconstruir sua realidade a partir dos elementos espirituais e materiais nela presentes, utilizar esses mesmos elementos para reedificar a realidade, sua história. Por realidade,

[...] são todas as dimensões que compóem nossa forma de viver e o espaço que a cerca. Em nosso caso, realidades sociais circunscrevemse às dimensões sociais, tanto àquelas que estão em nós quanto àquelas que nos circundam. Fazem parte delas igualmente nossas ideologias, nossas representações mentais, nossos símbolos, nossas crenças e valores, bem como nosso comportamento externo e os condicionamentos circundantes de ordem social. (DEMO, 2010, p. 27).

Nessa direção, considera-se a realidade como essencial para a construção das ciências sociais; nela estão os fenômenos: a forma objetiva e subjetiva de manifestar o passado, viver o presente e desejar o futuro - o vir-a-ser das relações sociais. Está na realidade o substrato da ciência: o locus das relações de força e poder que se tensionam contrárias; o espaço de criatividade e arte; de sublimação da existência humana; onde se nasce e morre; onde se procria e recria a vida e todas as suas formas de manifestar os valores humanos, para o bem ou para o mal.

$\mathrm{Na}$ realidade, o homem se depara com a necessidade de viver em conjunto, de se relacionar com as espécies, tão natural como social, vive num processo de interdependência com os recursos naturais e sociais. Nesse emergir de fenômenos que se completam, mas ao mesmo tempo se negam, as ciências sociais assumem a condição de interpretar, apreender e compreender como esses fenômenos acontecem, se potencializam e se renovam, numa constante dialética do de vir. Tornase relevante considerar que os elementos que compõem a história da humanidade manifestam-se de formas diferentes; no tempo presente esses elementos podem não ser visíveis e perceptíveis; outros se transformaram e se fazem presentes sob outros vieses e interpretações; e também, há aqueles que persistem e resistem ao tempo, 
recrudescidos e muitas vezes endurecidos, sem destonarem da forma cardeal de sua compreensão.

Este estudo apoia-se no método dialético por compreendê-lo enquanto capacidade de explicar a realidade e seus fenômenos; um caminho para as ciências sociais desvelar a realidade, o cotidiano e as manifestações que emergem das relações sociais em seu conjunto. Compreende-se que não seria o único caminho para as ciências sociais, mas a dialética permite apreender o movimento dos elementos, quando contrários, bem como as persistências históricas.

O cerne da dialética está que toda a realidade e as relações sociais nela presentes têm elementos contraditórios, bem como historicamente superáveis (DEMO, 2010). O movimento dialético tem inerente a ele a contradição e a negação, não no sentido de exclusão, mas de convivência e superação do fenômeno histórico. A dialética é por si só histórica, porque ser um processo contínuo e inacabado.

Ao considerar as ciências enquanto expressão da capacidade humana (ação objetiva e subjetiva), enquanto produto da realidade em movimento, ela traz em seu cerne a contradição em sua criação, capaz de se transformar e de se esgotar no tempo e espaço determinados, ou não, daí a compreensão das ciências tendo em sua essência as mediações histórica-humana-ética.

Nessa direção, as ciências sociais, assim como outros ramos das ciências, propõem a interpretação de determinado fenômeno e suas mediações, e a descoberta de algo novo, tendo como intenção que o resultado dessa construção promova $o$ progresso da sociedade, em seus diferentes matizes: cultural, econômico, político e social. As ciências, num todo, trazem no seu enredo essa função, a de promover e (re) inventar mecanismos e tecnologias para o bem da humanidade - é isso que se espera!

Todavia, para compreender essa função das ciências, em especial as ciências sociais, é necessário trazer à baila outro elemento fulcral, pois a partir dele que se direcionará para quem e para que das ciências - a ideologia:

[...] as ciências sociais são inevitavelmente ideológicas, porque são um fenômeno social, como qualquer outro. Ou seja, são construídas socialmente também ao sabor de um fluxo histórico movimentado por conflitos de desigualdade social. São também uma expressão de poder. Contêm uma justificação da sociedade em que se produzem. 
Tal justificação não lhes é algo extrínseco, oriundo do possível uso, mas algo intrínseco, interno, da própria tessitura delas. Não há ciência social que não seja ideológica (DEMO, 2010, p. 70).

Como esclarece o autor, a ideologia está intrínseca nas ciências sociais, mas percebê-la é tão importante quanto entender essa relação criticamente. Esgotar a ideologia das ciências sociais é algo quase que impossível, pois tal atitude seria uma nova forma de ideologia, ou seja, um enfrentamento ideológico de forças contrárias presentes na arena de poder.

A ideologia se apresenta como instrumento de justificação de algo imposto, pois, assim como outros fenômenos, as ciências sociais trazem a representação de quem a constrói, tem direção e intencionalidade. A ideologia está intrínseca nas diferentes correntes teóricas; na prática materializa-se em poder, sempre dominante, utilizando dessa força para a manutenção da ordem e reprodução social.

O poder dominante, imbricado por forças ideológicas, utiliza-nas para dominação das massas, pois sua força é naturalizada, sem percepção ou qualquer forma de criticidade. Na sociedade, esse poder ideológico se manifesta explicitamente na relação política construída, pois "A ideologia produz coesão social, porque se torna elemento identificador político. E é por isso que prepondera nela o lado político" (DEMO, 2010, p. 70). Para o poder dominante, tal coesão existe e é necessária para ordem e organização social, para manutenção da força política dominante e desmonte de qualquer contraideologia.

Pensar criticamente na tríade ciências-ideologia-poder político é considerar esses fenômenos sociais num processo de interdependência, que se retroalimentam e buscam a conservação da força social dominante do sistema capitalista. Não há como traçar essa análise sem compreender as forças em tensão na sociedade capitalista, que buscam incessantemente a permanência do status quo.

Desde a emersão do capitalismo, do seu processo transitório que vai da acumulação primitiva até o capitalismo industrial do século XVIII, é concreta a inovação das técnicas e da tecnologia para fins específicos: expansão e aumento do capital e, consequentemente, do lucro. Desde então, por passagens seculares, o capitalismo traz em seu bojo características próprias de apropriação de tudo que se cria e renova para seus fins. Habermas (1987, p. 68) elucida que "Desde o último quartel 
do século XIX fazem-se notar nos países capitalistas avançados [...] uma crescente interdependência de investigação técnica, que transformou as ciências na primeira força produtiva."

A ciência como força produtiva é reflexo da dominação do capital e de seu ideal, na construção de novas tecnologias que transitam desde o armamento bélico às indústrias farmacêuticas. Em plena expansão, as forças capitalistas, mesmo em colapso, utilizam de seu maior potencial - a mercantilização do capital financeiro, para o crescimento e inovação; reproduzem o consumismo exacerbado embutindo nas massas a necessidade de ter, pois tão natural quanto produzir é consumir. " $L a$ aceptación 'del desechar' como 'patrón' de relación social ocupa, boy, el lugar de la racionalidad formal y se ba extendido como arquitectura de toda interacción. Consumir es aprender a desechar y boy esa es la práctica massiva em nuetras sociedades." (SCRIBANO, 2015, p. 3).

Inova-se sem fronteiras, invadem-se territórios, culturas são devoradas pelo ideal consumista, a força do trabalho é explorada e esgotada até última gota, como água que seca na fonte e se renova logo a frente, por uma força que igual a traça devasta plantações. O que se faz das ciências e das tecnologias? Para quem se faz ciências e tecnologias? Elaborar uma análise para esses questionamentos requer uma compreensão crítica dessa relação ciência-capital que, à primeira vista, parecerá recorrente, mas não menos relevante.

A ciência atual tem enorme capacidade de gerar inovaçóes e saltos tecnológicos, adquirindo uma aureola mágica e determinista que a coloca acima da moral e da razão. A razão técnica parece ter lógica própria e poder ilimitado, legitimando-se por si mesma [...]. O deslumbramento diante da novidade tecnológica e a ausência total de valores éticos que definam limites e rumos poderão estar incubando tanto novos deuses, que conduzirão a humanidade à sua redenção, como serpentes cujos venenos ameaçarão sua própria sobrevivência. (DUPAS, 2001, p. 103).

A ciência sob os denodos do capital amplia suas forças de coesão e coerção, pois, instrumento de reprodução da ideologia do consumo nela inerente, faz das novidades tecnológicas algo essencialmente necessário para o ser humano, para sua sobrevivência. 
Com a expansão comercial e industrial, os avanços das pesquisas chegam à população mundial, por mídias e internet, e seus resultados e produtos apresentam-se como salutar à espécie humana, pois "Esse é o universo da satisfação imediata, que reduz a importância dada àquilo que toma tempo e a aceitação dos sacrifícios que isso impõe" (DUPAS, 2001, p. 54). O fetiche do consumo, inerente ao capitalismo, é reproduzido nesse processo; necessidades vazias e rápidas são suprimidas e renovadas, e num tempo rápido renovam-se as mercadorias e logo são essenciais e necessárias. Isso mantém o ciclo da produção e reprodução do capital - a produção de mercadoria e o consumo, e a exploração do trabalho, principalmente nos países periféricos ou subdesenvolvidos e em desenvolvimento.

Hoy, al igual que a principios del (siglo) XX, las 'nuevas' tecnologías se usan para: alcanzar cada vez mejores articulaciones entre deseos, objetos y subjetividades, para profundizar las sociabilidades normalizadas en el disfrute inmediato a través del consumo y crear vínculos, cada vez más fuertes, entre las vivencialidades y sensibilidades espectaculares/ sacrificiales (SCRIBANO, 2015, p. 3).

À luz do progresso sem fronteiras, Estados facilitam as transações financeiras de capital estrangeiro nesses países, o capital renova-se e oxigena-se por meio da exploração dos recursos humanos e naturais, das inovações tecnológicas e das ciências, em nome do lucro e do poder. Esse progresso não alcança a população mundial na mesma proporção e intensidade, pois ainda há regiões de apenas exploração, enquanto outras de exploração e consumo, ou seja, os produtos dessas inovações são distribuídos de acordo com a capacidade de consumo e poder aquisitivo de compra. Para além da capacidade de produção e consumo de mercadorias desse fluxo capitalista, o homem desenvolveu a capacidade de se autodestruir, algumas vezes de forma intencional e consciente.

Considera-se que os produtos das pesquisas e inovações tecnológicas não estão isentos da intencionalidade de quem os produziu. Quando houve a produção da bomba atômica e o avanço da indústria bélica no século XX, seu fim já era dado. Por que se produzem armas de destruição em massa, como as químicas, biológicas e nucleares? Para dominação, apenas?

Os cientistas que buscam o saber das ciências em suas diversas áreas as- 
sumem o papel ao qual se dispuseram - conhecer os elementos e fenômenos da natureza e as reações desses na formação do mundo. No entanto, o fazer ciência e tecnologia foi apropriado pelas grandes indústrias, são mercadorias de/para produção e consumo.

Com apoio dos Estados, tem financiamento e abertura nos mercados nacionais, incentivo para as pesquisas e produção. Tomando esse momento da produção de bens nocivos para a humanidade, creia-se que cientistas estejam envolvidos num processo de reprodução ideológica - entregues aos ditames do avanço econômico e do poder, bem como da criação científica. De acordo com Fernanda Sobral (2004), essa relação entre Estado, universidades e empresas forma uma tripla hélice no desenvolvimento científico e tecnológico, para o incentivo e apropriação do conhecimento, pois, pela globalização, as empresas investem em inovação tecnológica, com isso formam parcerias com as universidades e os governos. Essa compreensão utilitarista da ciência está explicitada quando "[...] a ciência passa a ser valorizada não apenas enquanto procura da verdade, mas também a partir de uma perspectiva de utilização" (SOBRAL, 2004, p. 224).

É necessário entender que a construção do conhecimento científico acontece numa relação entre diferentes esferas, de um lado o poder público representado pelo Estado e, de outro, o poder privado representado pelas empresas/ indústrias. Boaventura de Sousa Santos nos provoca a compreender esse processo da industrialização da ciência, tanto nos níveis de aplicação da ciência, como o de organização da investigação científica. No nível de aplicação da ciência, o autor chama a atenção nos feitos científicos que produziram grandes catástrofes para a humanidade e dessas ocorrências sistemáticas, a exemplo, as bombas de Hiroshima e Nagasaki. No nível da organização da investigação científica, o autor aponta dois efeitos principais nesse processo de industrialização da ciência, de um lado a proletarização dos cientistas e de outro o aumento da desigualdade tecnológica e científica entre os diferentes países do globo (SANTOS, 2010).

É forçosa a análise dispensada pelo autor, pois elucida a apropriação da ciência pelo capital, enquanto objeto de produção e reprodução desse sistema. Coaduna com a compreensão de que a ciência tornou-se ao mesmo tempo objeto e produto do capital financeiro, na expansão dos mercados e na apropriação e expro- 
priação da mão de obra. Para além do chão de fábrica que comumente é referido nesse processo de apropriação e expropriação da mão de obra, chamar-se-á atenção para o capital humano intelectual que muitas vezes não é visto nesse processo, tão quanto explorado e precarizado nas suas condições e organização do trabalho, está o cientista/pesquisador.

Os cientistas vivem a contradição dessa construção do conhecimento, tendo como principal capacidade o intelecto humano, produz e revive a condição humana de criar, renovar e atender às necessidades essenciais para a sobrevivência, bem como a criar produtos para o fetiche humano. Provocativo, Dupas (2001, p. 104) esclarece que "[...] o saber não pode, como tal, ser isolado de suas consequências."

Isso nos mostra que, por mais que os cientistas estejam absorvidos pelo ideal do capital e de seus agentes, Estado e indústrias, eles têm dentro de si a vontade de descobrir, inovar e recriar - sentidos de um pesquisador; ao mesmo tempo em que, enquanto trabalhador, vive as refrações do mundo do trabalho, estão expropriados do produto de seu trabalho; vivem sob os ditames das organizações científicas estatais e privadas e a mercê do produtivismo e utilitarismo ao qual a ciência e seus resultados se transformaram.

É necessário compreender o papel das ciências na sociedade, entendê-las enquanto instrumento de dominação e poder, mas também das possibilidades que estão na história da humanidade, das construções de conhecimento e técnica que promoveram e promovem o seu desenvolvimento. O grande desafio está na própria humanidade, em reconhecer como apropriou da ciência e da tecnologia, o que se fez dela; e como se apropriará das inovações tecnológicas. Além de reconhecer os impactos devastadores produzidos pela relação voltada estritamente para o poder e o lucro.

Grandes descobertas científicas são expoentes de pesquisas comprometidas com a humanidade e o planeta. A título de exemplo, quando se estuda o genoma humano para fins de tratamentos de doenças degenerativas, o avanço e incentivo para estudos na busca para a cura do câncer e da Síndrome da Imunodeficiência Adquirida (AIDS); quando as tecnologias da informação estão em uso para o bem coletivo, na ampliação do conhecimento político, no fortalecimento das práticas democráticas e das lutas contra as diversas formas de opressões; quando a informa- 
ção apresentada revela a crise ética do governo e o desmonte do Estado de Direito; quando se produz novas formas de reflorestamento de áreas devastadas pela ação do homem, na preservação de mananciais hídricos, na despoluição de mares e rios, entre outros. Com efeito,

A própria revolução científica e tecnológica e, sobretudo, o desenvolvimento dos meios de comunicação e informação possibilitam o processo de democratização e a interação de diferentes atores e de diferentes instituições no processo de produção do conhecimento. (SOBRAL, 2004, p. 224).

A grande questão está em quem tem acesso às inovações científicas e tecnológicas? Nessa mesma direção, Hugh Lacey (2008, p. 298) esboça o conhecimento científico enquanto patrimônio compartilhado da humanidade e, a partir daí, os benefícios das ciências para a humanidade.

Não desconsidero o ideal de que o conhecimento científico pertença ao patrimônio comum da humanidade. Na ciência moderna, obteve-se um enorme estoque de conhecimento confiável e de entendimento acerca de fenômenos do mundo, e muito desse conhecimento foi utilizado para informar incontáveis aplicações em tecnologia, medicina e outras áreas. Tais aplicações, amplamente avaliadas de modo positivo, têm contribuído fortemente para a transformação radical do mundo em que vivemos, na medida em que aumenta as capacidades humanas para agir e resolver problemas que até então permaneciam intratáveis.

Ao considerar que a construção das ciências gerou e gera um paradoxo entre ciência-poder-humanidade, partindo da compreensão que a produção das ciências e das tecnologias foram apropriadas para fins distintos, desencadeando malefícios e benefícios para a humanidade, chama-se a atenção para o impacto desse processo contínuo, inacabado e contraditório para os seres humanos. 


\section{OS DESAFIOS PARA AS CIÊNCIAS SOCIAIS NO INVERSO DA LÓGICA CAPI- TALISTA}

A partir dessas considerações, torna-se pertinente refletir os desafios postos para as ciências sociais em seu conjunto. Chamam-se para essa análise as ciências sociais por ser e ter elas o papel de interpretar e apreender os fenômenos sociais, mas é extremamente relevante destacar que tais ciências não conseguem responder à totalidade desses fenômenos, bem como produzir somente por elas respostas que venham a transformar a sociedade, pois "Fazer ciência social é em parte aprender a compreender outras visões e admitir a própria como preferencial, não porque não tenha defeitos, mas porque imaginamos menos defeituosa" (DEMO, 2010, p. 30).

Consideramos que as ciências sociais (CS) buscam nesse desvelar da realidade apreender e compreender como a sociedade reage às transformações societárias, reflexos dos diversos fatores que causam os novos arranjos sociais. Está nas CS a capacidade de entender e responder as transformações sociais e captar a essência humana, considerando que essas ciências têm referenciais teóricometodológicos para isso. As CS na atualidade visam interpretar a realidade e os fenômenos que nela emergem, romper com as imposições que cerceiam as diferentes expressões sociais e, principalmente, entender e promover respostas às demandas que surgem nesse contexto de barbárie. Na contramão do ideal produtivista, as CS vêm revelar os impactos desse ideal e permitir que os sujeitos sociais se apropriem do conhecimento enquanto produto social. É sobre esse conhecimento que o professor Clodoaldo Cardoso nos orienta que

A ciência moderna contém uma contradição interna precisamente no âmbito da ética: se, por um lado, o saber científico plenifica no ser humano realmente o sentido de sujeito (agente), de outro, esse próprio saber, que instaura o sujeito, vem destruindo as próprias condições de o ser humano realizar-se enquanto sujeito (CARDOSO, 1998, p. 4).

Essa contradição está na apropriação do conhecimento científico construído pelo homem sob a lógica do capital e como esse saber cientifico é aplicado. Nessa direção, novos questionamentos e reflexões emergem desafiadores: se o 
conhecimento científico é produto social, ou seja, pertence à humanidade como superar o domínio do sistema capitalista sobre os produtos de sua geração? Se o mesmo conhecimento que cria e renova pode destruir e gerar consequências nocivas à humanidade, como romper com essa lógica? Diante de um sistema capitalista que rege as relações sociais em seu conjunto e sendo as ciências impingidas por esse sistema, como o Estado incentiva a realização das pesquisas nas CS?

Entre os desafios contemporâneos para as ciências sociais está a de tornarem-se relevantes em meio ao grande incentivo financeiro às pesquisas científicas das áreas de tecnologia da informação, biotecnologia, engenharias, entre outras. É notório que Estados e empresas tenham interesses em áreas afins para a produção de ciências e tecnologias, principalmente aquelas em que seus produtos elevem a produção de bens e serviços, promovam o aumento do mercado nacional e internacional, e despertem o interesse das grandes transnacionais para o investimento em ações do capital financeiro nacional.

Tornar-se relevante em meio à mercantilização das ciências e tecnologias é tarefa árdua. É remar contra a maré do capital. Enquanto há dinheiro e incentivo para a realização das pesquisas em outras áreas, as ciências sociais em seu conjunto não têm o mesmo incentivo financeiro para a realização de suas pesquisas, pois "Não se investe em cientistas, técnicos e equipamentos para saber a verdade, mas para aumentar o poder" (DUPAS, 2001, p. 117).

Quando se arrisca a dizer que um dos grandes desafios das ciências sociais é tornar-se relevante, não estamos desconsiderando a construção histórica desse conjunto das ciências, nem mesmo do que ela hoje tem enquanto dimensão investigativa, propositiva, crítica, científica e ética, mas estamos apontando que, diante o investimento para as diversas áreas do conhecimento, observa-se uma diferença significativa de investimentos para as ciências sociais. Os Quadros 1 e 2 relacionam os investimentos às grandes áreas do conhecimento, conforme apresentadas pelo Conselho Nacional de Desenvolvimento Científico e Tecnológico (CNPq). 
Quadro 1. Painel de investimentos CNPq - 2014

\begin{tabular}{|l|c|c|c|}
\hline ESPECIFICAÇÃO & \multicolumn{3}{l|}{ Grandes áreas do conhecimento } \\
\hline MÉTRICA & \multicolumn{3}{l|}{ Valor (em mil reais) } \\
\hline ANO & 2014 & \multicolumn{2}{l|}{} \\
\hline Grande área & Bolsa no exterior & Bolsa no país & Auxílio à pesquisa \\
\hline Ciências exatas e da terra & 64.323 & 206.858 & 86.637 \\
\hline Ciências agrárias & 38.170 & 173.570 & 85.030 \\
\hline Ciências biológicas & 81.729 & 201.865 & 114.386 \\
\hline Ciências da saúde & 90.291 & 120.528 & 109.550 \\
\hline Ciências Humanas & 7.286 & 136.181 & 50.672 \\
\hline Engenharias e computação & 431.941 & 254.813 & 116.962 \\
\hline Línguas - letras e artes & 4.513 & 39.724 & 2.863 \\
\hline Outras (não especificadas) & 30.321 & 83.803 & 43.492 \\
\hline Sociais aplicadas & 59.521 & 122.946 & 22.010 \\
\hline
\end{tabular}

Fonte: Quadro elaborado por Cacildo Teixeira de Carvalho Neto, dados do Ministério da Ciência, Tecnologia, Inovações e Comunicações (2017).

Observa-se, no Quadro 1, referente ao ano de 2014, uma discrepância entre os valores de investimento da grande área das engenharias e computação para todas as outras áreas do conhecimento. Esse dado demonstra o interesse significativo do governo no desenvolvimento de tecnologias que coadunam aos interesses das grandes empresas, na produção de bens comerciáveis. No montante de bolsas no exterior, as ciências sociais aplicadas tiveram o investimento de 7,36\%; bolsas no país $9,17 \%$ e auxílio à pesquisa 3,48\%. 
Quadro 2. Investimentos CNPq - 2016

\begin{tabular}{|l|c|c|c|}
\hline ESPECIFICAÇÃO & \multicolumn{3}{l|}{ Grandes áreas do conhecimento } \\
\hline MÉTRICA & \multicolumn{3}{|l|}{ Valor (em mil reais) } \\
\hline ANO & 2016 & \multicolumn{2}{l|}{} \\
\hline \multicolumn{1}{|c|}{ Grande área } & Bolsa no exterior & Bolsa no país & Auxílio à pesquisa \\
\hline Ciências exatas e da terra & 2.746 & 199.415 & 83 \\
\hline Ciências agrárias & 1.180 & 174.796 & 34 \\
\hline Ciências biológicas & 2.727 & 195.242 & 6 \\
\hline Ciências da saúde & 1.192 & 117.652 & 4 \\
\hline Ciências humanas & 483 & 143.114 & 19 \\
\hline Engenharias ecomputação & 4.149 & 273.220 & 61 \\
\hline Línguas - letras e artes & 126 & 42.463 & Não informado \\
\hline Outras (não especificadas) & 666 & 82.844 & 1.651 \\
\hline Sociais aplicadas & 382 & 91.999 & 189 \\
\hline
\end{tabular}

Fonte: Quadro elaborado por Cacildo Teixeira de Carvalho Neto, dados do Ministério da Ciência, Tecnologia, Inovações e Comunicações (2017).

No ano de 2016, observa-se uma queda significativa de investimentos em todas as áreas de pesquisa, tanto para bolsas no exterior como bolsas no país e no auxílio à pesquisa. Para a grande área das engenharias e computação, o valor de investimento da bolsa no país foi a única que manteve a média em comparação ao ano de 2014, mas caiu nos outros investimentos. As ciências sociais tiveram 2,79\% de investimento para bolsa no exterior; 6,96\% para bolsa no país; e 9,23\% de auxílio à pesquisa, no montante de investimentos.

Sobre a queda de investimentos entre os anos de 2014 e 2016, Fabrício Marques (2017, p. 20, grifo nosso) descreve que

Em 2014, ano mais recente para o qual há estatísticas consolidadas, investiu-se no Brasil 1,27\% do Produto Interno Bruto (PIB) em atividades de P\&D (Pesquisa e Desenvolvimento), o equivalente a $\mathrm{R} \$$ 73,6 bilhões - e o quinhão do MCTIC (Ministério da Ciência, Tecnologia, Inovaçóes e Comunicações) (à época dividido em duas pastas) foi de $\mathrm{R} \$ 5,6$ bilhões, ou apenas 7,6\% desse investimento. Caso os cortes recentes não sejam revertidos, a participação do MCTIC no dispêndio nacional em P\&D deve cair de um patamar de $0,1 \%$ do PIB há três anos para um índice próximo a $0,07 \%$ do PIB neste ano. 
A queda dos investimentos em pesquisa e desenvolvimento impactam toda a produção e construção de conhecimento, em todas as grandes áreas das ciências. A falta de recursos gerará colapso nas universidades e, respectivamente, em seus programas de incentivo a pesquisa e de pós-graduação, interrompendo com pesquisas que estão em andamento e fechando portas para novas. A crise na ciência e na educação é reflexo do desmonte das políticas públicas e o congelamento dos investimentos que assolam o país, resultado de má gestão daquilo que é público e de seus recursos.

O Estado, ao diminuir os recursos para as pesquisas e inovações tecnológicas, abre uma porta de oportunidades para o investimento privado, para as grandes transnacionais que financiam pesquisas específicas com fins e mercados também específicos. Essas pesquisas são, em sua grande maioria, realizadas nas próprias indústrias, deixando fora desse circuito de investimentos as universidades.

$\mathrm{O}$ incentivo às grandes indústrias representa um saldo negativo significativo para os cofres públicos, pois a contrapartida é a destinação de recursos públicos para as empresas. Em 2014, o Brasil investiu 1,27\% do Produto Interno Bruto (PIB) em pesquisa e desenvolvimento, desse montante, 52,9\% de investimentos públicos e $47,1 \%$ do setor privado. De acordo com Fabrício Marques (2017, p. 22), para os investimentos em inovação, os setores, cujas empresas inovadoras investiram mais em atividades internas de pesquisa e desenvolvimento em 2014 (milhões de R\$), foram

[...] 2.913,2 para carros, reboques e carrocerias; 2.665,3 para coque, produtos derivados do petróleo e biocombustíveis; $1.966,4$ para produtos químicos; $1.555,7$ para informática, eletrônicos e ópticos; 1.367,9 para máquinas, aparelhos e material elétrico; 1.225 para produtos farmacêuticos; 1.122,8 outros equipamentos de transporte.

Os dados supracitados demonstram um incentivo localizado para a produção tecnológica de bens e serviços; ficando as ciências humanas, sociais e da saúde a cargo apenas do investimento público. O fator preocupante está na queda significativa de investimento do Estado para a pesquisa e desenvolvimento, como já apresentado, de 1,27\% do PIB em 2014 para 0,07\% em 2017.

Todo esse processo de financeirização e mercantilização das ciências e do 
conhecimento impactam diretamente a população e, com isso, geram novos fenômenos ou faz reviver questões há tempos sanadas. Cabe às ciências sociais desvelar esses fenômenos da sociedade e o cotidiano da população, bem como os impactos dos avanços tecnológicos e o retrocesso nesse contexto, nunca perdendo de vista que esse processo está enraizado nos valores do capital.

Se considerarmos as ciências enquanto instrumento de transformação, devemos sopesar que o avanço tecnológico traz em seu bojo a contradição de poder promover o progresso da humanidade, ao mesmo tempo ser objeto de destruição. Convive-se com "[...] a ambiguidade do progresso científico-tecnológico que passou do plano teórico para o existencial, ou seja, começamos a perceber na vida cotidiana a deterioração galopante do ambiente físico e social ao lado do mundo estonteante e maravilhoso da tecnologia" (CARDOSO, 1998, p. 1).

Gilberto Dupas (2005) nos esclarece dois caminhos, de redenção e destruição, no processo de apropriação da técnica, enquanto produto do conhecimento, capaz de alterar a vida, as condições de produção e o meio ambiente.

Se bem exercidas, submetidas aos interesses gerais das sociedades, poderão vir a ser um importante instrumento para o desenvolvimento da humanidade. Por outro lado, submetidas unicamente ao interesse do capital e de sua acumulação, essas mesmas tecnologias podem levar a efeitos sinistros e devastadores (DUPAS, 2005, p. 78-79).

O autor continua e expõe que o maior desafio será da humanidade em arbitrar esses caminhos, para assumir o controle social desse desenvolvimento estando a ciência sob a ordem do setor privado; e que o maior problema para isso está num Estado em fase de desmonte (DUPAS, 2005).

Nessa direção, Hugh Lacey (2008) elabora outros desafios para as ciências sociais na atualidade. O autor elucida que a ciência, enquanto patrimônio da humanidade, deve ser questionada sobre sua colaboração para a construção e fortalecimento de práticas e valores democráticos, com vistas à participação coletiva dos sujeitos na tomada de decisões. A pesquisa deve apreciar o valor social de seus resultados, os quais devem voltar à sociedade para que seus benefícios possam ser traduzidos em novos conhecimentos e esses absorvidos por essa sociedade. Deve, também, promover a integração educativa entre pesquisadores e população com 
vistas à colaboração participativa desses sujeitos para apreensão dos fenômenos sociais e da relação causal que os produzem, implementação de programas de educação científica nas universidades possibilitando a interação entre os diferentes sujeitos participantes das pesquisas, professores, alunos e diferentes servidores, colaborando na criação de agendas de debate para melhores condições de trabalho; além de "[...] o desenvolvimento e a promulgação de políticas públicas apropriadas que reflitam valores democráticos" (LACEY, 2008, p. 325).

As ponderações do autor são relevantes e provocativas se considerarmos o atual cenário político e econômico do país. Dificilmente as ciências sociais, sozinhas, responderiam a essas agendas levantadas por ele, mas temos que compreender o papel das ciências na sociedade e como ela pode colaborar em meio às esferas de poder (econômico, político e social) numa nova direção para a sociedade.

Nessa vereda é pertinente e urgente o diálogo das CS com outras áreas do conhecimento, enquanto caminho para compreender as relações construídas pelo ser humano em sua totalidade, seja entre os homens, seja com a natureza. Sobre as fronteiras disciplinares, Boaventura de Sousa Santos (2010) esclarece que

$\mathrm{Na}$ ciência moderna o conhecimento avança pela especialização. O conhecimento é tanto mais rigoroso quanto mais restrito é o objeto sobre que incide. Nisso reside, aliás, o que hoje se reconhece ser o dilema básico da ciência moderna: o seu rigor aumenta na proporção direta da arbitrariedade com que espartilha o real. Sendo um conhecimento disciplinar, tende a ser um conhecimento disciplinado, isto é, segrega uma organização do saber orientada para policiar as fronteiras entre as disciplinas e reprimir os que as quiserem transpor. É hoje reconhecido que a excessiva parcelização e disciplinarização do saber científico faz do cientista um ignorante especializado e que isso acarreta efeitos negativos. Esses efeitos são sobretudo visíveis no domínio das ciências aplicadas. (SANTOS, 2010, p. 74).

As especializações do conhecimento científico estão intrínsecas na ciência, enquanto produto do seu próprio desenvolvimento, as exigências postas pelas novas tecnologias levaram os pesquisadores a fragmentar e a hiperespecializar algumas áreas, e, para Boaventura Santos (2010), a busca por resolver essa parcelização e reducionismo fez gerar outras disciplinas acentuando ainda mais o conhecimento. 
Alguns caminhos para "minimizar" esse distanciamento estão na interdisciplinaridade e na transdisciplinaridade. Pela primeira entende-se como o diálogo entre as diferentes disciplinas para o mesmo objeto, preserva-se as especificidades de cada área do conhecimento e busca construir uma resposta comum. Na transdisciplinaridade, as disciplinas interagem sob o mesmo objeto, superam-se as especificidades de cada área, visando à construção de uma unidade do conhecimento. Outro caminho é a pluralidade metodológica, conhecimento imetódico, formado por uma constelação de métodos que responderá ao objeto de acordo com a realidade-espaço-tempo local (SANTOS, 2010).

\section{CONSIDERAÇÕES FINAIS}

O avanço tecnológico nas últimas décadas representa uma das maiores forças materializadas e contraditórias da sociedade, ao mesmo tempo em que é utilizado como fator de desenvolvimento econômico, sua produção está atrelada à exploração de mão de obra e dos recursos naturais em países periféricos e semiperiféricos. $\mathrm{O}$ avanço tecnológico traz benefícios para a sociedade se dele não houvesse formas desumanizantes de exploração e nocivas à natureza e se o acesso acontecesse de forma mais igualitária entre as mais diversas comunidades e sociedades. No entanto, o maior questionamento e desafio está em como produzir tecnologia na sociedade do capital com vistas ao acesso igualitário. Seria interesse desse sistema produtivo esse acesso? A resposta é não, pois a manutenção do atual sistema produtivo necessita dessa contradição e das suas formas de exploração e reprodução do valor do ter.

Todo esse processo gera refrações nas relações sociais, reflexos das mudanças e das (des)apropriações dos bens e valores, dos significados e sentidos que o homem tem das coisas e de si, às vezes se confundindo com aquele. Todas essas mudanças geram impacto direto na vida em sociedade e nas formas e representações que os homens têm de si e tomam para si. É sobre essas transformações e relações que as ciências sociais têm o desafio de apreender, interpretar e construir conhecimento.

Não se atribui às ciências sociais a responsabilidade de construir as repostas para as crises e degeneração material e espiritual da sociedade, mas cabe a seus 
pesquisadores debruçar sob a realidade, tensionar o debate e propor diante do caos possíveis caminhos e estratégias para prováveis mudanças. Estão no objeto de pesquisa desenvolvida por esses sujeitos as diversas formas de manifestações dos fenômenos sociais - da esfera de produção, das políticas sociais, da representação social, da estrutura e superestrutura, do pensamento humano etc., não isolados, mas num complexo que se interagem.

As pesquisas realizadas pelas CS têm essa propositura: desvelar aquilo que está encoberto, descortinar o cotidiano e revelar as formas de interações entre os homens, as instituições e o poder que emana dessa relação. A provocação em desenvolver esses estudos está na falta de interesse e fomento do Estado, como apresentado, nos últimos anos os recursos para as pesquisas das grandes áreas humanas e sociais diminuíram significativamente. Nesse último ano, 2017, demais áreas sofreram com a queda brusca dos investimentos, resultado da corrupção, da apropriação indevida dos bens públicos e da má gestão do Estado.

Nessa realidade, o desafio de fazer ciência e tecnologia está para todos os pesquisadores de todas as áreas do conhecimento que dependem do Estado para financiar suas pesquisas e promover o acesso de seus resultados a população/ sociedade a qual se destina a prática científica. Para sanar essa problemática, o governo estreita as parcerias com as empresas privadas, as quais investem em pesquisas, mas essas com fins definidos - a geração de produtos comerciáveis nacional e internacionalmente.

A reflexão aqui elaborada não é de oposição às ciências e às novas tecnologias, mas de tensionar a forma de sua produção, o nexo mercadológico que apropriou do conhecimento humano, a manutenção da miséria humana em todos seus sentidos, com a finalidade do desenvolvimento econômico de poucos países. Aos países periféricos e semiperiféricos, fica a apropriação das tecnologias de supérfluos, tendo a mídia como seu produto e força aliada para ilusionar que esses produtos são essenciais e capazes de suprir a necessidade e a felicidade humana. 


\section{REFERÊNCIAS}

ANDERY, M. A. P. A. et al. Para compreender a ciência: uma perspectiva histórica. Rio de Janeiro: Garamond, 2014.

CARDOSO, C. M. Ciência e ética: alguns aspectos. Revista Ciência e Educação, Bauru, v. 5, n. 1, p. 1-6, 1998. Disponível em: <www.scielo.br/pdf/ciedu/v5n1/ a01v5n1.pdf>. Acesso em: 5 fev. 2017.

DEMO, P. Introdução à metodologia da ciência. São Paulo: Atlas, 2010.

DUPAS, G. Ética e poder na sociedade da informação: de como a autonomia das novas tecnologias obriga a rever o mito do progresso. São Paulo: Ed. Unesp, 2001.

DUPAS, G. Atores e poderes na nova ordem global: assimetrias, instabilidades e imperativos de legitimação. São Paulo: Ed. Unesp, 2005.

HABERMAS, J. Técnica e ciência como “ideologia”. Tradução de Artur Morão. Lisboa: Ed. 70, 1987.

MARQUES, F. Financiamento em crise. Pesquisa FAPESP, São Paulo, n. 261, p. 20-29, nov. 2017. Disponível em: < http://revistapesquisa.fapesp.br/wp-content/ uploads/2017/06/020_financiamento_256.pdf > . Acesso em: 3 nov. 2017.

MINISTÉRIO DA CIÊNCIA, TECNOLOGIA, INOVAÇÕES E COMUNICAÇÕES. Painel de investimentos. Brasília, DF, 2017. Disponível em: < http://cnpq.br/painel-deinvestimentos > . Acesso em: 12 out. 2017.

PONTES, R. N. Mediação e Serviço Social: um estudo preliminar sobre a categoria teórica e sua apropriação pelo serviço social. São Paulo: Cortez, 2010.

SANTOS, B. S. Um discurso sobre as ciências. São Paulo: Cortez, 2010. 
SCRIBANO, A. Comienzo del Siglo XXI y Ciencias Sociales: un rompecabezas posible. Polis Revista Latinoamericana, Santiago, n. 14, v. 41, p. 1-11, 2015. Disponível em: <www.scielo.cl/pdf/polis/v14n41/art15.pdf > . Acesso em: 11 nov. 2017.

SOBRAL, F. Desafios das ciências sociais no desenvolvimento científico e tecnológico contemporâneo. Sociologias, Porto Alegre, ano 6, n. 11, p. 220-237, jan./jun. 2004. Disponível em: < www.scielo.br/pdf/soc/n11/n11a10.pdf > . Acesso em: 13 ago. 2017.

Recebido em: 01/10/2018

Aceito em: 14/11/2018 